\title{
The crystallomics pipeline, a shotgun approach on native proteomes to (re)discover the unsuspected
}

\author{
S. Engilberge, ${ }^{1,2}$ O. Lemaire, ${ }^{3}$ M-C. Mueller, ${ }^{3}$ F. Leonarski, ${ }^{1}$ C-Y. Huang, ${ }^{1}$ T. Tomizaki, ${ }^{1}$ A. Royant, ${ }^{2,4}$ V. Olieric, ${ }^{1}$ \\ M. Wang, ${ }^{1}$ T. Wagner ${ }^{3}$
}

1Swiss Light Source, Paul Scherrer Institut, Forschungsstrasse 111, Villigen-PSI, 5232, Switzerland., 2European Synchrotron Radiation Facility, 38043 Grenoble, France., 3Max-Planck-Institut für Marine Mikrobiologie, Celsiusstraße 1, 28359, Bremen, Germany, 4Institut de Biologie Structurale (IBS), Universite' Grenoble Alpes, CEA, CNRS, 71 avenue des Martyrs, Grenoble Cedex 9, 38044, France

sylvain.engilberge@esrf.fr

Recombinant protein overproduction can lead to aggregation and aberrant artefacts due to the intrinsic specificities of proteins and the requirement of physiological factors $\left(\mathrm{O}_{2}\right.$ or light-sensitivity, partners, chaperones, cofactors and post-translational modifications requirements). The Wagner's group (MPI Bremen) has developed a native shotgun approach baptized Crystallomics (Figure) to directly explore native protein complexes from anaerobic microorganisms that contain numerous exotic cofactors (e.g. iron-sulfur cluster). ${ }^{1,2}$ After protein extraction, the soluble proteome is fractionated through successive chromatography types and the selective process of crystallisation is used as an ultimate purification step. Since this approach targets the most abundant proteins from the soluble fraction, a significant amount of protein crystals representative of the microorganism's metabolic landscape have been obtained. Ab initio phasing was systematically used for the X-ray structure determination of these unidentified proteins. Crystals were sorted based on their colours. Sulfur-SAD ${ }^{3,4}$ were performed on the transparent crystals by collecting high multiplicity and multiorientations data at low energies on X06DA at the Swiss Light Source or on BL-1A at KEK. To reduce noise and improve the accuracy of the data quality some of the protein crystals were shaped with a deep-UV laser (to decrease X-ray absorption) and diffraction experiments were performed under helium environment with the recently developed PSI JUNGFRAU detector. ${ }^{5}$ For coloured crystals containing their native cofactors and heavy elements, X-ray fluorescent spectra were systematically measured. SAD were then performed at the edge of the atom of interest. Protein targets were then identified either by manual sequencing in the electron density maps or by fold similarity after reconstruction of a poly-alanine model. In complement to X-ray diffraction, in cristallo $\mathrm{UV} /$ vis absorption spectra were recorded by using the microspectrophotometer $i c \mathrm{OS}^{6}$ at the ESRF to further investigate the nature of the state adopted by metal/absorbing centers. This synergistic approach proved that crystallisation not only separates proteins from each other but is also a powerful tool to isolate and characterized different protein states from a mixture.

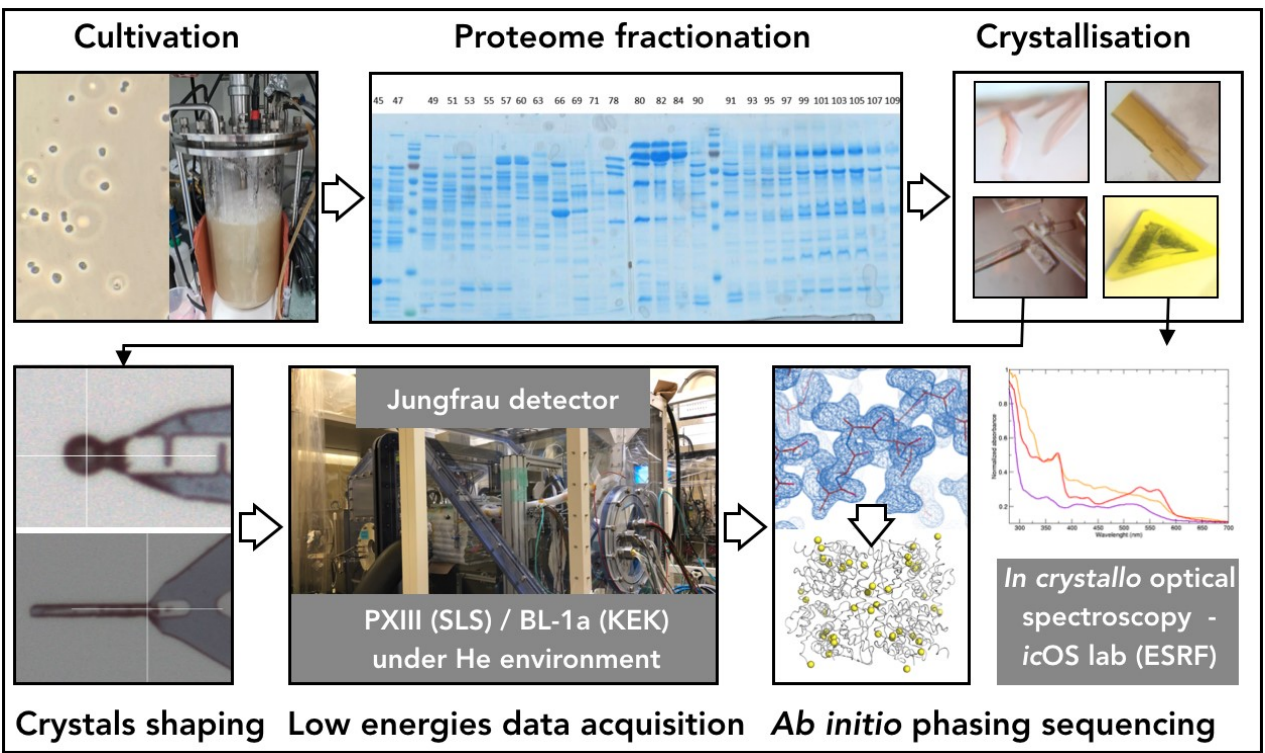


[1] Vögeli B, Engilberge S, Girard E, Riobé F, Maury O, Erb TJ, Shima S, Wagner T. (2018) Proc. Natl. Acad. Sci. U S A. 27, 3380-3385.

[2] Engilberge S., Wagner T., Santoni G., Breyton C., Shima S., Franzetti B., Riobé F., Maury O., Girard E. (2019) J. Appl. Cryst. 28, $722-731$.

[3] Olieric V., Weinert T., Finke A. D., Anders C., Li D., Olieric N., Borca C.N., Steinmetz M.O., Caffrey M., Jinek M., Wang M. (2016) Acta Cryst. $D$ 72, 421-429.

[4] Basu S, Olieric V, Leonarski F, Matsugaki N, Kawano Y, Takashi T, Huang CY, Yamada Y, Vera L, Olieric N, Basquin J, Wojdyla JA, Bunk O, Diederichs K, Yamamoto M, Wang M. (2019) IUCrJ. 6, 373-386.

[5] Leonarski F, Redford S, Mozzanica A, Lopez-Cuenca C, Panepucci E, Nass K, Ozerov D, Vera L, Olieric V, Buntschu D, Schneider R, Tinti G, Froejdh E, Diederichs K, Bunk O, Schmitt B, Wang M. (2018) Nat. Methods. 15, 799-804.

[6] von Stetten D, Giraud T, Carpentier P, Sever F, Terrien M, Dobias F, Juers DH, Flot D, Mueller-Dieckmann C, Leonard GA, de Sanctis D and Royant A. In crystallo optical spectroscopy (icOS) as a complementary tool on the macromolecular crystallography beamlines of the ESRF. (2015) Acta Crystallogr. D, 71, 15-26.

\section{Keywords: Native purification; crystallisation; ab initio phasing; Sulfur-SAD; JUNGFRAU; in crystallo spectroscopy}

This work was supported by grants from the Paul Scherrer Institute and the Max Planck Society. We acknowledge financial support from Swiss National Science Foundation grant number 200021_182369. 